\title{
MAINSTREAM AND SPECIAL EDUCATION TEACHERS' IMPLEMENTATION OF DIFFERENTIATED INSTRUCTION
}

\author{
Mariyam Shareefa ${ }^{*}$ \\ Universiti Brunei Darussalam, (UBD), Brunei Darussalam \\ (Email: maree2098@gmail.com) \\ Rohani Hj Awg Mat Zin² \\ Universiti Brunei Darussalam, (UBD), Brunei Darussalam \\ (Email: rohani.matzin@ubd.edu.bn) \\ Nor Zaiham Midawati Abdullah ${ }^{3}$ \\ Universiti Brunei Darussalam, (UBD), Brunei Darussalam \\ (Email: norzaiham.abdullah@ubd.edu.bn) \\ Rosmawijah Jawawi ${ }^{4}$ \\ Universiti Brunei Darussalam, (UBD), Brunei Darussalam, \\ (Email: rosmawijah.jawawi@ubd.edu.bn)
}

Accepted date: 21-04-2019

Published date: 08-07-2019

To cite this document: Shareefa, M., Zin, R. A. M., Abdullah, N. Z. M., \& Jawawi, R. (2019). Mainstream and Special Education Teachers' Implementation of Differentiated Instruction. International Journal of Education, Psychology and Counseling, 4(31), 260-268.

DOI: $10.35631 /$ IJEPC.4310022

\begin{abstract}
This study examines the difference between mainstream teachers and Special Education Needs (SEN) teachers' implementation of Differentiated Instruction (DI) in Maldivian schools. A total of 64 teachers (32 mainstream teachers and 32 SEN teachers) were randomly selected, and data were collected using survey $(N=64)$ and classroom observation $(N=8)$. Independent sample t-test was adopted to analyse survey data, while mean scores of the rating scale were used to analyse observation checklist. Findings revealed that there is no significant difference between the two groups of teachers' implementations. Both mainstream teachers and SEN teachers adopt DI at a very low level. Hence, findings suggest that despite the special training, and the importance of DI to SEN students, SEN teachers did not implement DI at any higher level than mainstream teachers. Therefore, a review of training programs conducted for both mainstream teachers and SEN teachers are found necessary.
\end{abstract}

Keywords: Differentiated Instruction, Implementation, Mainstream Teachers, Special Education Needs (SEN) Teachers

\section{Introduction}

For effective curriculum delivery, all teachers especially those who teach students with special needs require to have a wide repertoire of instructional strategies that cater diverse student

\footnotetext{
${ }^{*}$ Corresponding author
} 
needs (Vlachou, Didaskalou, \& Voudouri, 2009). Teachers need to have a thorough understanding of the instructional strategies and implement them consistently so that students with learning and other difficulties in their classes will succeed alongside their peers. Differentiated Instruction (DI) is one such strategy that literature shows as effective for both SEN teachers and mainstream teachers in maximising student learning (Deunk, Smale-Jacobse, de Boer, Doolaard, \& Bosker, 2018; Tomlinson, 1999).

Although the main role of both mainstream teachers and Special Education Needs (SEN) teachers is taking the responsibility for the education of all pupils in their classes, SEN teachers are required to perform additional duties that provide academic intervention and support for children with unique and demanding needs. Hence, in comparison to their colleagues of mainstream teachers, serving as an advocate and a teacher for special education, a SEN teacher is obliged to become more knowledgeable, skilled, and professionally autonomous and committed (O'Gorman \& Drudy, 2011).

In the context of Maldives, although all mainstream schools are considered as inclusive schools, some schools have established integrated special classes for students with specific disabilities. Teachers who are exclusively trained in special education teach in these integrated classes. During the training of these SEN teachers, a central focus is given to inclusive instructional strategies such as DI and its application. Parallel to the special classes of SEN, due to the advocacy of inclusive education, some mild and moderate level SEN students attend mainstream classes, and therefore, similar to SEN teachers, mainstream teachers are also obliged to adopt pedagogical differentiation in their teaching.

Although differentiated instruction is highly recommended to replace the one-size-fit-all curriculum and instructions, implementation of the differentiated instructional strategies is complex and not without difficulty (Tomlinson, 1999). Often, teachers misunderstand the purpose of differentiated instruction, and the result is teachers' hesitancy towards adopting the strategies. Incorporating effective differentiated instructional strategies in the lesson at the same time meeting the requirements of mandated, standardized, high-stakes testing leave teachers under increased pressures (Dixon et al., 2014). Some teachers have reported feeling frustrated with the complications involved in the practice, whereas others think they are implementing these strategies but in fact are not (Dee, 2011). On top of that, teachers who truly do differentiate their instruction may also not do it on a regular basis to ensure that all students learn (Nedellec, 2015).

Although, DI implementation is extensively studied in literature, there is a paucity of research to compare the use of DI by both SEN teachers and mainstream teachers. Therefore, we believe that it is important to study the matter as it would provide important implications for further improvement in enhancing education of diverse learners both in integrated and mainstream classrooms. As such, the main objective of this study is to investigate the differences between mainstream teachers and SEN teachers' implementation of DI in Maldivian schools. The study also aims to understand the overall status of Maldivian teachers' use of DI in their teaching and learning processes.

\section{Literature Review}

The theoretical basis of this investigation is the Differentiated Instruction (DI) model of Tomlinson (2014). DI is a principle-guided approach in which teaching and learning is structured through four specific elements: curriculum, assessment, instruction, and 
environment (Tomlinson \& Imbeau, 2013). According to the DI model, instructional delivery takes place in four different forms: content, process, product, and learning environment (Tomlinson, 2014). Content is the materials or mechanisms through which the learning is accomplished. Process is the sense making acitivities, and Products represent what students have learned and the skills they have acquired. Environment is an evolving community of learners that are engaged with learning (Santangelo \& Tomlinson, 2009, 2012, Tomlinson, 2001, 2014). For inclusion of students with disabilities in general education system, implementation of the above four DI components is considered as a prerequisite (Strogilos, Avramidis, Voulagka, and Tragoulia, 2018).

A large repertoire of studies have declared DI as an effective strategy to address a wide range of diverse learners (see: Joseph, Thomas, Simonette, \& Ramsook, 2013; Santangelo \& Tomlinson, 2012; Tomlinson, 1999; Tomlinson \& Imbeau, 2014). Despite the positive aspects of DI, great deal of studies in the literature have found that DI implementation is infrequent and inconsistent in many classrooms (Kamarulzaman, Azman, \& Zahidi, 2017; MorrisonThomas, 2016). Research also has shown that numerous reasons existed for teachers not using DI on a regular basis (Joseph et al., 2013; Roiha, 2014; Siam \& Al-Natour, 2016; VanTasselBaska \& Stambaugh, 2005). Amongst these factors, lack of accurate knowledge is one major obstacle found hindering teachers' efforts.

Nonetheless, teachers who work in DI based inclusive classrooms have to be trained with adequate knowledge that facilitates learning opportunities for all the students (Alhassan \& Abosi, 2014). More importantly, teachers who work with students of special needs require to have in-depth skills and knowledge of DI strategies that create conditions for learning of their students. DI would assist SEN teachers' modifications and accommodations of learners' profiles that help achieving their students' Individual Education Plan (IEP) goals. Indisputably, when teachers are skilled in using DI to modify and accommodate curriculum components, they will understand how to achieve IEP without much struggles (Dee, 2011).

Hence, in relation to the above notion of knowledge discrepancy between mainstream and SEN teachers, it could be believed that SEN teachers would have better use of DI than mainstream teachers. Participants in King's (2010) study also believed that, SEN teachers' implementation would be higher because, they are typically trained to differentiate as they have to work with students of varied abilities and disabilities. However, reviewed literature shows a great deficiency in investigating implementation of DI strategies especially between these two types of teachers. Among the few available studies, Whipple (2012) explored how often both these two cohorts of teachers use differentiation for their students, and the analysis revealed that SEN teachers' use of DI is higher than mainstream teachers. SEN teachers in that study got a mean score of 90.78 while mainstream teachers had a mean score of 85.52. Apparently, there is hardly any research that could be used to compare these findings. Hence, owing to this scarcity of empirical evidence, more research is needed to confirm and verify these results.

\section{Method}

The study employed parallel or concurrent mixed methods (Tashakkori, Teddlie, \& Sines, 2013) and hence, data were collected concurrently using the methods of descriptive survey and classroom observations. The population of the study was all elementary level mainstream teachers and SEN teachers working in Maldivian schools. Amongst these population, a sample of 64 teachers (32 mainstream teachers and 32 SEN teachers) were randomly selected and, all the samples $(\mathrm{N}=64)$ were surveyed while, eight teachers' classroom lessons were observed 
twice. For the survey, an adapted questionnaire of McMillan (2011) was used. The survey questionnaire had two sections; (1) demographic information and, (2) a Likert-type scale in which the items measured teachers' implementation of differentiated instruction. For the observation, a checklist together with a rubric adapted from Differentiated Instruction Implementation Matrix (DIIM) (Downes, 2006) and Maeng (2011) were used. The survey data were analysed using independent sample $t$-test while mean scores of the checklist were used to analyse observation data. The analysis of the survey was done using SPSS version 21.0. Prior to the analysis, reliability test was conducted, and the results indicated that the scale of the survey obtained a score of .927 indicating very good internal consistency (Pallant, 2007).

\section{Survey Results}

An independent samples $t$-test was conducted to determine if there was a significant difference between the mainstream teachers and SEN teachers' DI implementation. The analysis was done based on the four respective components of the DI model (content, process, product, and environment). The means and standard deviation scores for both teacher groups are shown in Table 1.

As seen from the Table 1, the mean scores indicate that the specific components of DI have a small difference between mainstream teachers and SEN teachers. For instance, the largest difference in mean scores is obtained for the component of process whereby the mean scores for mainstream teachers and SEN teachers are 59.8 and 57.5 respectively. The results indicated that Levene's test was not significant, suggesting that equal variances can be assumed. Hence, only the first row of the results is reported in Table 2 .

Table 1: Implementation of DI Components by Mainstream Teachers and SEN Teachers

\begin{tabular}{llllll}
\hline Components & Teacher Type & N & Mean & $\begin{array}{l}\text { Std. } \\
\text { Deviation }\end{array}$ & $\begin{array}{l}\text { Std. Error } \\
\text { Mean }\end{array}$ \\
\hline \multirow{2}{*}{ Content } & Mainstream teachers & 32 & 21.1 & 3.9 & 0.7 \\
& SEN teachers & 32 & 20.5 & 3.6 & 0.6 \\
\multirow{2}{*}{ Process } & Mainstream teachers & 32 & 59.8 & 10 & 1.8 \\
& SEN teachers & 31 & 57.5 & 7.8 & 1.4 \\
\multirow{2}{*}{ Product } & Mainstream teachers & 32 & 28.5 & 6 & 1.1 \\
& SEN teachers & 31 & 27.8 & 4.3 & 0.8 \\
& Mainstream teachers & 32 & 19.2 & 4.4 & 0.8 \\
& SEN teachers & 32 & 18.4 & 3.6 & 0.6 \\
\hline
\end{tabular}

According to the results of the $t$-test, there is no significant difference between mainstream teachers and SEN teachers in relation to DI implementation by, Content, $t(62)=0.60, p>.05$; Process $t(61)=1.00, p>.05$; Product, $t(61)=0.53, p>.05$; and Environment, $t(62)=0.81$, $p>.05$. The magnitude of differences in the mean for content and product were very small, eta squared $=0.006$ and 0.005 respectively (mean difference for content $=0.56,95 \% \mathrm{CI}$ : -1.30 to 2.42; mean difference for product $=0.69,95 \%$ CI: -1.93 to 3.32). However, the magnitude of differences in the mean for process and environment were small, eta squared $=0.016$ and 0.010 respectively (mean difference for process $=2.26,95 \% \mathrm{CI}$ : -2.26 to 6.79 ; mean difference for environment $=0.81,95 \% \mathrm{CI}:-1.20$ to 2.83 ) 
Table 2: Difference Between Mainstream Teachers and SEN Teachers' Implementation of DI

\begin{tabular}{|c|c|c|c|c|c|c|c|}
\hline & \multirow[t]{2}{*}{$t$} & \multirow[t]{2}{*}{$\mathrm{df}$} & \multirow{2}{*}{$\begin{array}{l}\text { Sig. (2- } \\
\text { tailed) }\end{array}$} & \multirow{2}{*}{$\begin{array}{l}\text { Mean } \\
\text { Difference }\end{array}$} & \multirow{2}{*}{$\begin{array}{l}\text { Std. Error } \\
\text { Difference }\end{array}$} & \multicolumn{2}{|c|}{$\begin{array}{l}95 \% \text { CI of the } \\
\text { Difference }\end{array}$} \\
\hline & & & & & & Lower & Upper \\
\hline Content & 0.60 & 62.00 & .55 & 0.56 & 0.93 & -1.30 & 2.42 \\
\hline Process & 1.00 & 61.00 & .32 & 2.26 & 2.26 & -2.26 & 6.79 \\
\hline Product & 0.53 & 61.00 & .60 & 0.69 & 1.31 & -1.93 & 3.32 \\
\hline Environment & 0.81 & 62.00 & .42 & 0.81 & 1.01 & -1.20 & 2.83 \\
\hline
\end{tabular}

\section{Observation Results}

A similar trend was found from the analysis of classroom observations. The observation checklist had seven different domains. These seven domains were: quality curriculum and lesson design, preparation for learning and response to learner needs, instructional practices, classroom routines, student assessment, positive and supportive learning environment, and evidence of differentiation. Under each of these domains, there were three to five items that correspond to the key indicators of DI. These items were given in four different levels of proficiency: novice, apprentice, practitioner, and expert. A rubric of Downes (2006) was modified and used to guide scoring these items. Analysis of the domains on DIIM provided detailed explanation of the level of DI practices teachers adopted in their teaching.

The analysis of the items on the observation checklist revealed that the novice, apprentice, practitioner, and expert level competency exhibited by mainstream teachers and SEN teachers were almost equal. Table 3 presents details of these competencies demonstrated by each teacher in the respective domains. Table 4 depicts a comparison between mainstream teachers and SEN teachers' total number of times each proficiency is displayed.

Table 3: Teachers' Total Scores for The Respective Domains Mainstream teachers SEN Teachers

\begin{tabular}{lllllllll}
\hline & T1 & T2 & T3 & T4 & T5 & T6 & T7 & T8 \\
\hline D1 & A & A & P & A & N & P & P & A \\
D2 & N & N & P & P & N & P & E & N \\
D3 & N & N & P & P & N & P & P & A \\
D4 & N & A & P & P & N & P & P & A \\
D5 & A & A & P & P & A & A & A & A \\
D6 & N & A & E & P & N & P & E & P \\
D7 & N & N & A & P & N & A & P & N \\
\hline
\end{tabular}

Notes: N, novice; A, apprentice; P, practitioner; E, expert

D1, Quality Curriculum and Lesson Design; D2, Preparation for Learning and Response to Learner Needs; D3, Instructional Practices; D4, Classroom Routines; D5, Student Assessment; D6, Positive, Supportive Learning Environment; D7 Evidence of Differentiation 
As indicated in Table 3 and 4, both mainstream and SEN teachers' observed lessons were almost at the same level in terms of proficiency in using differentiation in teaching. The slightest variation was on the practitioner and expert level. In this regard, SEN teachers demonstrated one competency more at the expert level compared to mainstream teachers. Similar difference was observed at practitioner level where mainstream teachers performed slightly better than SEN teachers.

Table 4: Teachers' Total Scores for Each Proficiency Level

\begin{tabular}{lllll}
\hline & Novice & Apprentice & Practitioner & Expert \\
\hline Mainstream teachers & 8 & 8 & 11 & 1 \\
SEN teachers & 8 & 8 & 10 & 2 \\
\hline
\end{tabular}

\section{Discussion}

The aim of this study is to investigate the difference between mainstream teachers and SEN teachers' implementation of DI in Maldivian schools. Surprisingly, the study finds that there is no significant difference between the two groups of teachers' DI implementation. The analysis revealed unexpected results because, in the context of the study, SEN teachers receive exclusive and in-depth training on special education and differentiated instruction strategies compared to their colleagues of mainstream teachers. As yielded from both the findings of the survey and observations, the practice of differentiated instruction utilised by both SEN teachers and mainstream teachers was low in all areas of content, process, product, and environment. The observation results show that, Domain 7 which indicates the evidence of differentiation (specifically based on content, process, product, and environment) revealed that same number of teachers were at novice $(n=2)$, apprentice $(n=1)$, practitioner $(n=1)$, and expert $(n=1)$ level in each group of teachers.

Although differentiated instruction is widely recommended (Subban, 2006; Tomlinson, 2005), and experimented (Hobson, 2008; Melesse, 2015; Reis, Mccoach, Little, Muller, \& Kaniskan, 2011), literature lacks much empirical studies which have compared implementation of DI between mainstream teachers and SEN teachers explicitly. Among the few available studies, Whipple's (2012) empirical findings revealed contrasting results to what was found in the current study. It was discovered that unlike the present study, SEN teachers in Whipple's (2012) study implement DI strategies better than mainstream teachers in overall.

Literature shows numerous studies that show teachers' use of DI as inconsistent and infrequent (Brevik, Gunnulfsen, \& Renzulli, 2018; Chien, 2015; Driskill, 2010; Tomlinson, 2005). Moosa and Shareefa (2019), and Nedellec (2015) argue that a major factor for this inconsistency is teachers' lack of accurate pedagogical content knowledge. Melesse (2015), and VanTasselBaska and Stambaugh (2005) also reported that among several reasons, the primary cause for the absence of DI in the classroom stemmed from a lack of the necessary content knowledge. Hence, further studies are needed to identify and confirm teachers' knowledge competency and other contributing factors for mainstream and SEN teachers' implementation of DI strategies distinctively.

\section{Conclusions and Implications}

The results of this study revealed that there is no significant difference in mainstream teachers and SEN teachers' implementation of differentiated instruction in Maldivian schools. 
Accordingly, the results yielded that implementation of DI among mainstream teachers and SEN teachers is marginal. It was found that despite the special training, and the importance of DI to SEN students, SEN teachers did not implement DI at any higher level than mainstream teachers. Hence, it implies the importance of integrating differentiated instruction at different levels of the education system: (1) at national level, policy makers to strengthen incorporating DI into the national curriculum implementation, (2) universities and teacher training institutes to include relevant content on teachers' pre-service and in-service training (3) schools to encourage and reassure that the application of DI in teaching is a continuous and consistent practice of both mainstream teachers and SEN teachers so that learning of all ability students is possible.

Despite its significant contribution to literature, there are several weaknesses that may limit the validity and generalisability of the study's findings. The study used a mixed approach with survey and observation as the method of data collection. Hence, it was not possible to identify why the difference was insignificant. An additional enquiry of a semi-structured interview could elicit the underlying reasons for teachers' lack of using DI in teaching. Further, the sample has only 64 teachers hence, it warrants a large-scale descriptive study which entails rigorous analysis that could enable generalisation of the findings.

\section{References}

Alhassan, A.-R. K., \& Abosi, O. C. (2014). Teacher Effectiveness in Adapting Instruction to the Needs of Pupils With Learning Difficulties in Regular Primary Schools in Ghana. SAGE Open, Vol 4, Iss 1 (2014) VO - 4, (1).

Brevik, L. M., Gunnulfsen, A. E., \& Renzulli, J. S. (2018). Student teachers' practice and experience with differentiated instruction for students with higher learning potential. Teaching and Teacher Education, 71, 34-45.

Chien, C.-W. (2015). Analysis of Taiwanese elementary school English teachers' perceptions of, designs of, and knowledge constructed about differentiated instruction in content. Cogent Education, 2(1), 1-16.

Dee, A. L. (2011). Preservice teacher application of differentiated instruction. School of Education, George Fox University, 46(1), 53-70.

Deunk, M. I., Smale-Jacobse, A. E., de Boer, H., Doolaard, S., \& Bosker, R. J. (2018). Effective differentiation Practices: A systematic review and meta-analysis of studies on the cognitive effects of diff erentiationpractices in primary education. Educational Research Review Journal, 2018(24), 31-54.

Downes, D. M. (2006). Designing evaluation tools for the differentiated instruction staff development initiative. (Doctoral Dissertation). Available from ProQuest Dissertations $\&$ Theses. (Order No. 3247697).

Driskill, K. M. (2010). A qualitative study of teacher understanding and use of differentiated instruction to promote reading achievement. (Doctoral Dissertation). Available from ProQuest Dissertations \& Theses. (Order No. 3437433).

Hobson, M. L. (2008). An analysis of differentiation strategies used by middle school teachers in heterogeneously grouped classrooms. (Doctoral Dissertation). Available from University of North Carolina Wilmington.

Joseph, S., Thomas, M., Simonette, G., \& Ramsook, L. (2013). The impact of differentiated instruction in a teacher education setting: Successes and challenges. International Journal of Higher Education, 2(3), 28-40.

Kamarulzaman, M., Azman, H., \& Zahidi, A. (2017). Differentiated instruction strategies in English language teaching for gifted students. Journal of Applied Environmental and Biological Sciences, 7(June), 78-90. 
King, S. (2010). Factors associated with inclusive classroom teachers' implementation of differentiated instruction for diverse learners. uest Dissertations \& Theses. (Order No. 3433402).

Maeng, J. L. C. (2011). Differentiating science instruction: Success stories of high school science teachers. (Doctoral Dissertation). Available from ProQuest Dissertations \& Theses. (Order No. 3484516).

Mastropieri, M. A., Scruggs, T. E., Norland, J. J., Berkeley, S., McDuffie, K., Tornquist, E. H., \& Connors, N. (2006). Differentiated curriculum enhancement in inclusive middle school science. The Journal of Special Education, 40(3), 130-137.

McMillan, A. (2011). The relationship between professional learning and middle school teachers' knowledge and use of differentiated instruction. (Doctoral Dissertation). Available from Walden University.

Melesse, T. (2015). Differentiated instruction: Perceptions, practices and challenges of primary school teachers. Science, Technology and Arts Research Journal, 4(3), 253-264.

Moosa, V., \& Shareefa, M. (2019). The impact of teachers' experience and qualification on efficacy, knowledge and implementation of differentiated instruction. International Journal of Instruction, 12(2).

Morrison-Thomas, N. (2016). Exploring teachers 'experiences of differentiated instruction: A qualitative case study. (Doctoral Dissertation). Available from ProQuest Dissertations \& Theses. (Order No. 10140347).

Nedellec, C. M. (2015). Teachers' understanding of differentiated instruction in Swiss elementary schools. (Doctoral Dissertation). Available from ProQuest Dissertations \& Theses. (Order No. 3718012).

O'Gorman, E., \& Drudy, S. (2011). Professional development for teachers working in special education / inclusion in mainstream schools: The views of teachers and other stakeholders. Belfield, Dublin.

Reis, S. M., Mccoach, D. B., Little, C. A., Muller, L. M., \& Kaniskan, R. B. (2011). The effects of differentiated instruction and enrichment pedagogy on reading achievement in five elementary schools. American Educational Research Journal, 48(2), 462-501.

Santangelo, T., \& Tomlinson, C. A. (2009). The application of differentiated instruction in postsecondary environments: Benefits, challenges, and future directions. International Journal of Teaching and Learning in Higher Education, 20(3), 307-323.

Santangelo, T., \& Tomlinson, C. A. (2012). Teacher educators' perceptions and use of differentiated instruction practices: An exploratory investigation. Action in Teacher Education, 34(4), 309-327.

Strogilos, V., Avramidis, E., Voulagka, A., \& Tragoulia, E. (2018). Differentiated instruction for students with disabilities in early childhood co-taught classrooms: types and quality of modifications. International Journal of Inclusive Education, (May), 1-19.

Subban, P. (2006). Differentiated instruction: A research basis. International Education Journal, 7(7), 935-947.

Tashakkori, A., Teddlie, C., \& Sines, M. C. (2013). Utilizing Mixed Methods in Psychological Research. In Handbook of Psychology, Research Methods in Psychology. New Jersey: John Wiley \& Sons, Inc.

Tomlinson, C. A. (1999). The differentiated classroom: Responding to the needs of all learners. Alexandria, Va: Association for Supervision and Curriculum Development.

Tomlinson, C. A. (2001). How to Differentiate Instruction in Mixed Ability Classrooms (Vol. 37). Alexandria: Association for Supervision and Curriculum Development.

Tomlinson, C. A. (2005). Travelling the road to differentiation in staff development. National Staff Develpment Council, 26(4), 8-12. 
Tomlinson, C. A. (2014). The Differentiated Classroom: Responding to the Needs of All Learners. Review of Educational Research (Vol. 85). Alexandria, VA: Association for Supervision and Curriculum Development.

Tomlinson, C. A., \& Imbeau, M. B. (2010). Leading and Managing A Differentiated Classroom. Virginia: ASCD Publications.

Tomlinson, C. A., \& Imbeau, M. B. (2013). Differentiated instruction: An integration of theory and practice. The Handbook of Educational Theories.

VanTassel-Baska, J., \& Stambaugh, T. (2005). Challenges and possibilities for serving gifted learners in the regular classroom. Theory Into Practice, 44(3), 211-217.

Vlachou, A., Didaskalou, E., \& Voudouri, E. (2009). Mainstream teachers' instructional adaptations: implications for inclusive responses. Revista De Educacion, (349), 179201.

Whipple, K. A. (2012). Differentiated instruction: A survey study of teacher understanding and implementation in a Southeast Massachusetts School District. (Doctoral Dissertation). Available from ProQuest Dissertations \& Theses. (Order No. 3525802). 